\author{
К.В. Ивашкин ${ }^{1, *}$, Е.А. Изатуллаев ${ }^{2}$, В.Р. Корнеева ${ }^{1}$ \\ ${ }^{1}$ ФГАОУ ВО «Первый Московский государственный медииинский университет им. И.М. Сеченова» \\ (Сеченовский Университет) Министерства здравоохранения Российской Федерачии, Москва, Российская Федерация \\ ${ }^{2}$ Казахстанский национальный медицинский университет им. С.Д. Асфендиярова, \\ Центр гастроэнтерологии и эндоскопической диагностики, Астана, Республика Казахстан
}

Цель: проанализировать механизм действия и эффективность защиты слизистой оболочки (CO) желудочнокишечного тракта (ЖКТ) в рамках актуальных схем лечения на примере метилметионинсульфония (витамина U) и представить возможности его применения при эрозивно-язвенном поражении различной этиологии.

Основные положения. Понятие «гастропротекция» включаетв себя не только предотвращение повреждения при воздействии агрессивных агентов, но и ускорение процессов заживления в условиях сохраненной секреции соляной кислоты. Простагландины (ПГ) и SH-антиоксиданты служат ключевыми медиаторами «гастропротекции» при остром и хроническом повреждении. SH-содержащие эндогенные субстанции (L-цистеин, D,L-метионин, GSH) и экзогенные молекулы (метилметионинсульфония хлорид (MMSC), N-ацетилцистеин) предотвращают повреждение благодаря своей способности поглощать/нейтрализовывать свободные радикалы, образующиеся при клеточном повреждении под воздействием ксенобиотиков, ингибировать экспрессию TNF-a, уменьшать аспирин-индуцированную адгезию лейкоцитов к эндотелию, стимулировать высвобождение муцина. В эксперименте MMSC предотвращал этанол-индуцированное повреждение СО жКТ, стимулировал высвобождение муцина и перераспределение его на поверхность СО, в клинических исследованиях MMSC успешно поддерживал ремиссию дуоденальной язвы.

Заключение: для усиления основных схем лечения и поддержания ремиссии при эрозивно-язвенном поражении верхних отделов ЖКТ в качестве вспомогательного средства могут выступать препараты, оказывающие защитное воздействие на гастродуоденальную слизистую оболочку, в частности метилметионинсульфония хлорид (витамин U).

Ключевые слова: желудочная цитопротекция, витамин U, метилметионинсульфония хлорид, простагландины, SH-антиоксиданты

Конфликт интересов: публикация выполнена при поддержке ООО «Юнифарм».

Для цитирования: Ивашкин К.В., Изатуллаев Е.А., Корнеева В.Р. Желудочная цитопротекция как основа защиты и восстановления слизистой оболочки желудочно-кишечного тракта при эрозивно-язвенном поражении различной этиологии. Российский журнал гастроэнтерологии, гепатологии, колопроктологии. 2020;30(5):7-17. https://doi.org/10.22416/1382-43762020-30-5-1

\title{
Gastric Cytoprotection as Basis of Gastrointestinal Mucosa Protection and Repair in Erosive Ulcerative Lesions of Various Aetiologies
}

Konstantin V. Ivashkin ${ }^{1,{ }^{\star}}$, Eldos A. Izatullaev², Vasilisa R. Korneeva ${ }^{1}$

${ }^{1}$ Sechenov First Moscow State Medical University (Sechenov University), Moscow, Russian Federation
${ }^{2}$ Asfendiyarov Kazakh National Medical University, Astana, Kazakhstan

Aim. Assessment of efficacy and the mechanism of action of gastrointestinal mucosa (GM) protection in current treatment settings with methylmethionine-sulfonium chloride (vitamin $U$ ) to illustrate its applicability in erosive ulcerative lesions of various aetiologies. 
Key points. Aside to damage prevention in exposure to aggressive agents, gastroprotection implies healing promotion under the preserved level of hydrochloric acid secretion. Prostaglandins (PG) and SH-antioxidants are key mediators of gastroprotection in acute and chronic damage. SH-containing endogenous substances (L-cysteine, $\mathrm{D}, \mathrm{L}-$ methionine, GSH) and exogenous molecules (methylmethionine-sulfonium chloride (MMSC), $\mathrm{N}$-acetylcysteine) prevent damage due to the ability to absorb/neutralise free radicals released in xenobiotic-triggered cell damage, inhibit TNF- $\alpha$ expression, reduce the aspirin-induced leukocyte-endothelium adhesion and stimulate mucin release. In experiment, MMSC prevented the ethanol-induced GM damage, stimulated mucin release and its redistribution on the GM surface; in clinical trials, MMSC effectively facilitated remission in duodenal ulcer.

Conclusion. Preparations exerting a protective effect on gastroduodenal mucosa, such as methylmethionine-sulfonium chloride (vitamin $\mathrm{U}$ ), may improve basic treatment settings and facilitate remission in erosive ulcerative lesions of upper gastrointestinal tract.

Keywords: gastric cytoprotection, vitamin U, methylmethionine-sulfonium chloride, prostaglandins, SH-antioxidants

Conflict of interest: the work was supported by "Unifarm" LLC.

For citation: Ivashkin K.V., Izatullaev E.A., Korneeva V.R. Gastric Cytoprotection as Basis of Gastrointestinal Mucosa Protection and Repair in Erosive Ulcerative Lesions of Various Aetiologies. Russian Journal of Gastroenterology, Hepatology, Coloproctology. 2020;30(5):7-17. https://doi.org/10.22416/1382-4376-2020-30-5-1

Частота выявления инфекции Helicobacter pylori в различных регионах РФ достигает 65$92 \%$ в соответствии в актуальными на сегодняшний день «Клиническими рекомендациями Российской гастроэнтерологической ассоциации по диагностике и лечению инфекции Helicobacter pylori у взрослых» [1]. Клинические рекомендации «Рациональное использование нестероидных противовоспалительных препаратов» [2] сообщают о том, что в 2016 г. в РФ было зарегистрировано 19,2 млн людей с заболеваниями костно-мышечной системы, большинство из которых в составе базовой терапии принимают нестероидные противовоспалительные препараты (НПВП), а в 2019 г. объем продаж этих лекарственных средств (ЛС) составил более 530 млн упаковок (по данным IQVIA (IMS Health and Quintiles), 2019). Таким образом, наиболее значимыми этиологическими факторами развития поражения слизистой оболочки (CO) желудочно-кишечного тракта (ЖКТ) являются инфекция H. pylori (с ней ассоциированы хронический гастрит, язвенная болезнь и другие заболевания) и НПВП (НПВП-гастропатия, НПВП-энтеропатия и др.). Несмотря на высокую эффективность разработанных схем эрадикационной терапии $H$. pylori, включающих пути преодоления резистентности к антибиотикам, не все задачи возможно решить при их помощи. Стабилизация патологического процесса, предотвращение прогрессирования морфологических изменений $\mathrm{CO}$, стимуляция процессов регенерации и метаболизма, а также восстановление функционального состояния желудка и его поддержание на должном уровне в период ремиссии требуют дополнительных мер по защите слизистой ЖКТ. Все вышеперечисленное способствует повышению колонизационной резистентности желудка и препятствует повторному инфицированию [3]. Рассматривая проблему НПВП-гастропатии, стоит отметить, что не менее чем в 40-50\% случаев кровотечения из верхних отделов ЖКТ, потребовавшие эндоскопического гемостаза, обусловлены приемом НПВП [4, 5]. Несмотря на широкое применение ингибиторов протонной помпы (ИПП) для профилактики кровотечений, этот подход не является универсальным: по данным E. Washio и соавт., применение ИПП повышает риск развития НПВП-энтеропатии [6]. В таких обстоятельствах в арсенале специалистов должны присутствовать дополнительные препараты для защиты СО ЖКТ с различными механизмами действия, направленными на повышение устойчивости $\mathrm{CO}$ к неблагоприятным воздействиям. Все это укладывается в рамки современной концепции 4Р-медицины (predictive, preventive, personalized, participatory), где приоритетным является индивидуальный, учитывающий особенности каждого пациента подход к лечению [7].

Данный обзор преследует цель проанализировать механизм действия и эффективность защиты слизистой оболочки желудочно-кишечного тракта в рамках актуальных схем лечения на примере метилметионинсульфония (витамина U) и представить возможности его применения при эрозивноязвенном поражении различной этиологии.

\section{Эволюция представлений о желудочной} цитопротекции

Для формирования полноценной картины стоит рассмотреть историю желудочной цитопротекции с момента первого описания этого явления A. Robert в конце 1970-х. Интересно, что первоначальной задачей ученого было продемонстрировать клиническую значимость препарата простагландина (ПГ) как нового антисекреторного ЛС, выпущенного на рынок фармацевтической компанией Upjohn $[8,9]$. A. Robert и его коллеги практически случайно обнаружили, что малые дозы ПГ предотвращают развитие не только аспирин-индуцированных эрозий, но и алкоголь-индуцированного геморрагического поражения СО желудка на животной модели, причем этот эффект реализовался в условиях сохраненной кислотопродукции. Результаты этих 
открытий были описаны в ряде работ [8, 9, 11], где этому феномену дано определение «желудочная иитопротекция», подразумевающее предотвращение повреждения желудка, индуцированного химическими (этанол, кислоты, основания, гипертонические растворы) или физическими агентами (высокие температуры), при применении субтерапевтических доз ПГ [10, 11]. Эти важные выводы привлекли внимание научных сообществ разных стран и послужили стимулом для дальнейших исследований. P.H. Guth и соавт. первыми показали, что «иитопротективными» свойствами обладают не только ПГ, но и некоторые другие препараты (циметидин, пропантелин в дозах, не угнетающих желудочную секрецию) [12]. Этот факт натолкнул S. Szabo и соавт. на закономерное предположение: если вещества с разной химической структурой выступают в роли «цитопротекторов», то в основе может лежать единый эндогенный механизм действия (гормональная регуляция / антиоксидантные свойства сульфгидрильной группы SH). Немногим позже в серии экспериментов на крысах было доказано, что желудочная цитопротекция, вызванная ПГ и циметидином, была обусловлена эндогенным синтезом глюкокортикоидов, поскольку после адреналэктомии (но не после тиреоидэктомии и овариоэктомии) эффект цитопротекции исчезал, а затем восстанавливался при введении глюкокортикоидов (но не минералокортикоидов) [13, 14]. За этим последовало и еще одно важное открытие: гастротоксические препараты/яды истощают запас глутатиона (GSH, ключевого антиоксидантного фактора),

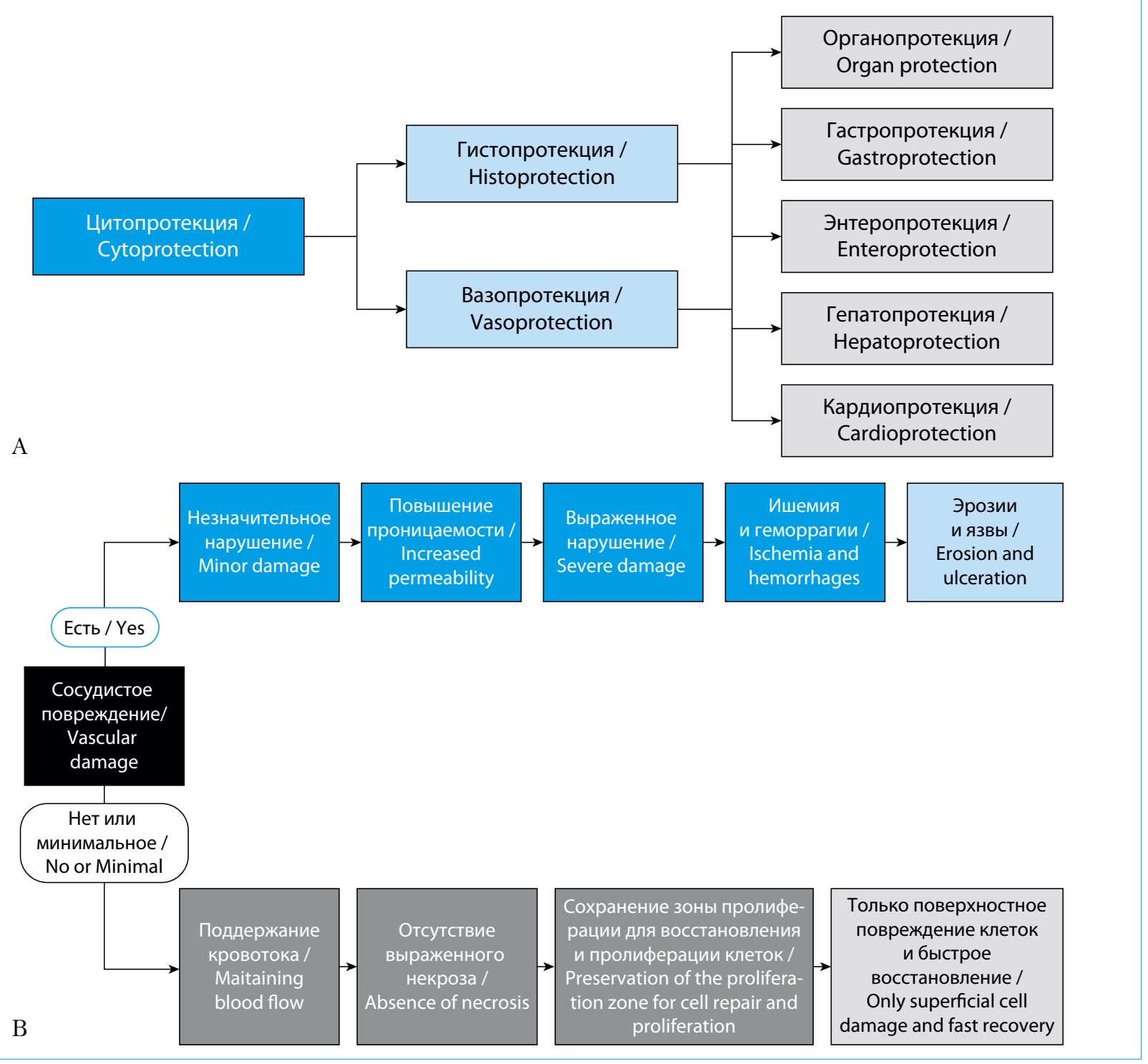

Рис. 1. Основа для эволюции понятия «желудочная цитопротекция»: последовательность сосудистых изменений и связанных с ними нарушений слизистой оболочки с гастропротекторной предварительной обработкой (А) или без нее (B)

Fig. 1. Rationale of "gastric cytoprotection": sequence of vascular changes and associated mucosal lesions with (A) and without (B) gastroprotective pre-treatment 
содержащегося в слизистой оболочке желудка крыс, a введение $\mathrm{SH}-$ содержащих препаратов (L-цистеин, $\mathrm{N}$-ацетилцистеин, цистеамин, метионин), в свою очередь, предотвращало этанол- и кислот-индуцированное повреждение СО ЖКТ у крыс [14, 15]. Дальнейшая работа в области «желудочной цитопротекции» в 1980-х годах преподнесла «большой сюрприз», так как стало известно, что предотвращение повреждения СО ЖКТ не только реализуется опосредованно (т.е. через эндогенные модуляторы - глюкокортикоиды и SH-антиоксиданты), но и морфологически ограничено макроскопическим уровнем. A. Robert и соавт. рассматривали только макроскопические препараты CO ЖКТ через 1 час после введения ПГ. Какова была картина на микроскопическом уровне? Ответы на этот вопрос содержатся в работах E.R. Lacy и S. Ito [16, 17], а также S. Szabo и соавт. [18, 19]: каждый из коллективов авторов, изучавших разные агенты, независимо друг от друга пришел к выводу, что SH-антиоксиданты [18, 19] и ПГ [16, 17] предотвращали только возникновение геморрагий и некроза, но не повреждение покровного эпителия. Дальнейшие гистологические исследования выявили, что при премедикации практически любым известным на то время «цитопротектором» (циметидином, ПГ, SH-антиоксидантами) повреждения, индуцированные этанолом, были минимизированы за счет того, что патологические процессы не захватывали эндотелий субэпителиально расположенных сосудов, а сохранившиеся шеечные клетки из ямок в течение часа мигрировали на поверхность СО, тем самым закрывали ее поверхностные дефекты [16, 17]. Из этого следует, что «цитопротекторы» предотвращают острое сосудистое повреждение и последующее кровотечение, а не неизбежную гибель клеток желудочного эпителия [18]. Исследования с применением световой и электронной микроскопии также подтверждали данный факт [18, 19]. Таким образом, было предложено считать термин «цитопротекция» некорректным, так как клетки желудочного эпителия неминуемо гибнут под воздействием агрессивных факторов, одновременно при этом происходит быстрая репарация, что обеспечивается сохраняющимся адекватным кровоснабжением СО ЖКТ. Обеспечение же нормального кровотока в капиллярах является основной функцией «протекторов». Результатом этих взаимодействий служит сохранение нормальной гистологической структуры и функции желудка, то есть «гастропротекция» [14].

В настоящее время общепринятой считается концепция о том, что местные защитные факторы СО ЖКТ представляют собой единую систему и включают три уровня: предэпителиальный (слизисто-бикарбонатный слой), эпителиальный (покровный эпителий, гистологический барьер) и субэпителиальный (микроциркуляторное русло) [20]. Более развернутая характеристика уровней представлена в таблице 1 [21]. Не стоит упускать из внимания наличие и центрального звена регуляции защиты СО ЖКТ, открытого в первой половине 1980-х годов (рис. 2).

\section{Таблища 1. Защитные факторы слизистой оболочки желудка}

Table 1. Gastric mucosa protective factors

\begin{tabular}{|c|c|}
\hline $\begin{array}{l}\text { У ровень } \\
\text { Level }\end{array}$ & $\begin{array}{l}\text { Характеристика } \\
\text { Character }\end{array}$ \\
\hline \multirow[t]{4}{*}{$\begin{array}{l}\text { Предэпителиальный } \\
\text { Pre-epithelial }\end{array}$} & $\begin{array}{l}\text { Компоненты желудочного сока ( } \mathrm{HCl}, \mathrm{IgA}) \\
\text { Components of gastric acid ( } \mathrm{HCl}, \mathrm{IgA})\end{array}$ \\
\hline & $\begin{array}{l}\text { Непрерывный слой слизи, муцин и фосфолипиды } \\
\text { Unstirred mucus layer, mucin and phospholipids }\end{array}$ \\
\hline & $\begin{array}{l}\text { Бикарбонаты, механизм ощелачивания при приеме пищи } \\
\text { Bicarbonate, alkaline tide }\end{array}$ \\
\hline & $\begin{array}{l}\text { ПГ, стимулирующие синтез слизи и бикарбонатов } \\
\text { PGs inducing mucus and bicarbonate production }\end{array}$ \\
\hline \multirow[t]{3}{*}{$\begin{array}{l}\text { Эпителиальный } \\
\text { Epithelial }\end{array}$} & $\begin{array}{l}\text { Непрерывный слой эпителиальных клеток, трефойловые пептиды, белки иннантного } \\
\text { иммунитета } \\
\text { Continuous layer of surface epithelial cells, trefoil peptides, innate immunity peptides }\end{array}$ \\
\hline & $\begin{array}{l}\text { Постоянное быстрое обновление желудочного эпителия, факторы роста, ингибиторы } \\
\text { апоптоза (сурвивин) } \\
\text { Continuous epithelium renewal, growth factors, apoptosis inhibitors (survivin) }\end{array}$ \\
\hline & $\begin{array}{l}\text { Стимуляция заживления эпителия ПГ } \\
\text { PG-induced epithelium repair }\end{array}$ \\
\hline \multirow[t]{3}{*}{$\begin{array}{l}\text { Субэпителиальный } \\
\text { Subepithelial }\end{array}$} & $\begin{array}{l}\text { Микроциркуляторное русло } \\
\text { Mucosal microcirculation }\end{array}$ \\
\hline & $\begin{array}{l}\text { Клетки эндотелия, вазодилататоры }\left(\mathrm{NO}, \Pi_{2}\right) \\
\text { Endothelial cells, vasodilators (NO, PGI })\end{array}$ \\
\hline & $\begin{array}{l}\text { Стимуляторы ангиогенеза (PDGF, dFGF) } \\
\text { Angiogenesis stimulators (PDGF, dFGF) }\end{array}$ \\
\hline
\end{tabular}




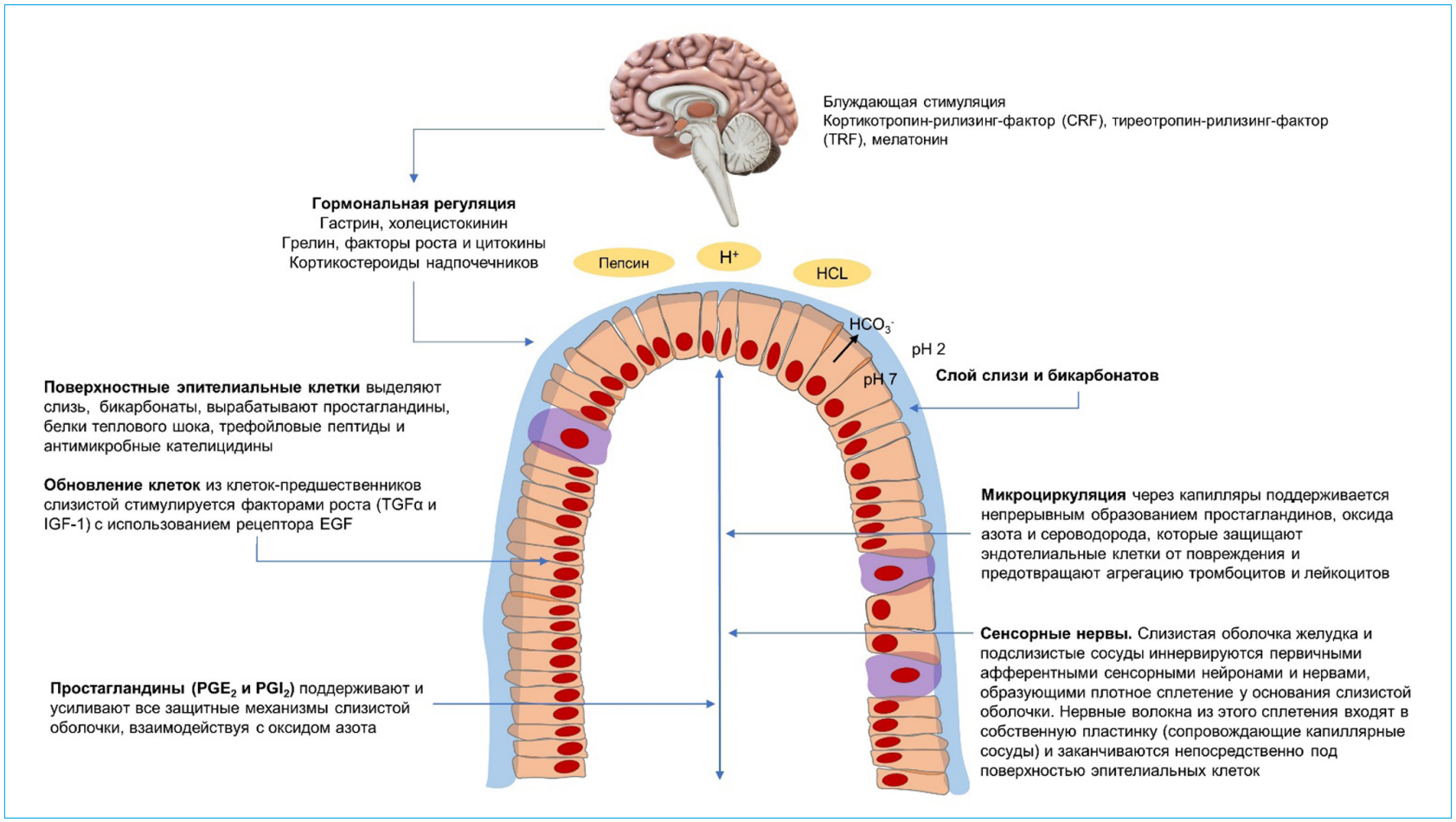

Рис. 2. Распределение защитного слоя слизи

Fig. 2. Protective mucus allocation

Таким образом исследования, некоторые из которых представлены выше, и накопленные за 40 лет данные и опыт свидетельствуют о том, что механизмы защиты СО ЖКТ представляют из себя многогранную, сложную динамическую систему. Тем не менее, рассматривая отдельные ее компоненты, зачастую непросто разобраться, один ли универсальный механизм лежит в основе работы всей системы или несколько. Какой механизм можно считать ведущим? С помощью каких механизмов некоторые «гастропротекторы» оказывают свои эффекты при остром и хроническом повреждении? Все эти вопросы важны для практической медицины, задачей которой является поиск путей эффективной помощи для всех и каждого конкретного пациента.

\section{Механизмы «гастропротекции» \\ при остром повреждении}

S. Szabo и соавт. [12, 15, 18, 22, 23] подчеркивают особую роль двух эндогенных субстанций - ПГ и SН-антиоксидантов, считая их ключевыми медиаторами «гастропротекции» при остром повреждении. Еще в 1983 г. на животной модели было проведено исследование [17, 23], которое включало оценку результатов посредством световой микроскопии. В результате проведенного опыта было установлено, что премедикация крыс раствором ПГ не предотвратила непосредственную гибель клеток эпителия СО ЖКТ, но способствовала более эффективному восстановлению ее исходного состояния, поскольку повреждение не распространялось глубже, чем на $1 / 5$ толщины CO, и не захватывало капилляры. В то же время макропрепараты СО ЖКТ не демонстрировали никаких видимых изменений. Аналогичными были и результаты исследования с применением SHантиоксидантов [12].

Происхождение этот феномена раскрыто в работах P. Guth и соавт. [23, 24]: при воздействии химических агентов на СО ЖКТ капиллярный кровоток сначала замедляется, а затем через $1-2$ мин и вовсе останавливается, в противовес этому предварительное применение ПГ- и $\mathrm{SH}-$ содержащих препаратов способствует поддержанию кровотока на физиологическом уровне, без чего энергозависимый процесс миграции шеечных клеток на поверхность слизистой оболочки и последующая репарация невозможны $[18,19]$. В свою очередь, обеспечение кровотока прямо зависит от сохранности функции эндотелия (синтезируемые интактным эндотелием $\mathrm{NO}$ и $\Pi_{2} \mathrm{I}_{2}$ предотвращают агрегацию тромбоцитов и лейкоцитов и, следовательно, тромбозы, а также обладают вазодилатирующей функцией) [25]. Поэтому раннее повреждение эндотелия, индуцированное этанолом и другими химическими агентами, определяет возникновение эрозивно-язвенных дефектов СО ЖКТ. Последовательность событий при остром повреждении слизистой оболочки раскрыта S. Szabo и соавт. [22]: спустя 1-3 минуты после интрагастральной инсталляции 75\%-го раствора этанола происходит повреждение эндотелия и увеличивается проницаемость сосудов, а поверхностные геморрагические повреждения появляются 
только на 5-10-й минуте. Аналогичные данные, подтвержденные электронной микроскопией, были получены A. Tarnawski и соавт. [26] в ходе экспериментов на биоптатах СО желудка здоровых волонтеров. Получается, что если подобное повреждение развивается по законам эволюционно сложившегося патофизиологического процесса острого воспаления с фазами сосудистой (повышенная проницаемость, приводящая к транссудации плазмы и местному отеку) и клеточной реакции (лейкоцитарная инфильтрация, которая вносит вклад в тромбообразование) [27], то ПГ, которые по своей сути относятся к медиаторам воспаления, в этом процессе выполняют множество функций: противодействие вазоконстрикторам ( $\mathrm{LTC}_{4}, \mathrm{TXA}_{2}$, эндотелин), предотвращение агрегации и адгезии к эндотелию тромбоцитов и лейкоцитов, подавляют активацию тучных клеток [21]. Безусловно, это неполный перечень функций, однако актуальный в рамках механизма поддержания кровотока.

По данным G. Mozsik и соавт. [28], а также B.M. Peskar [29], расширение капилляров, увеличение проницаемости сосудистой стенки, приводящее к локальному периваскулярному отеку, увеличению кровотока (что на макроскопическом уровне выглядит как гиперемия), регулируется в том числе и работой капсаицин-чувствительных нейронов. Нервные волокна плотной сетью охватывают lamina propria $\mathrm{CO}$, где сопровождают сосуды, и достигают субэпителиальной области. Поэтому стимуляция нервных окончаний повреждающими агентами (в т. ч. соляной кислотой и капсаицином - алкалоидом перца) приводит к активации кислоточувствительных ионных каналов нервных окончаний и непосредственному влиянию на тонус артериол через нейротрансмиттерный каскад (высвобождение CGRP - вазодилатация) [21, 30]. ПГ не принимают участия в защите, инициированной системой капсаицин-чувствительных нейронов [29]. Стоит отметить, что этот механизм реализуется при воздействии умеренного количества стимуляторов-ирритантов, тогда как хроническое и/ или высокодозное введение повреждающих агентов (капсаицина в том числе) приводит к «химической абляции» афферентного звена нейронов и уменьшает резистентность к повреждению [29, $31,32]$. Таким образом, несмотря на то что выраженное увеличение проницаемости сосудов и отек при воспалении, сопровождающие любое повреждение, являются реакциями патологическими, сами по себе приводящими к ишемии ткани, аналогичные явления, но выраженные умеренно, направлены на протекцию. Это механистическое объяснение созвучно с описанным в свое время феноменом «адаптивной цитопротекции» [33, 34].

Нельзя оставить без внимания еще один важный механизм защиты - синтез муцина и бикарбонатов. Слизь, покрывающая эпителий желудка, выполняет важную физиологическую функцию: формирование плотного стабильного слоя, где происходит нейтрализация кислоты и рН у непосредственной поверхности эпителия поддерживается на практически нейтральном уровне [35]. Обязательным условием является достаточное количество $\mathrm{HPO}_{3}^{-}$, а муцин, в свою очередь, необходим для формирования геля как его ключевая структурная единица. Если рассмотреть молекулярную структуру мультимера муцина, обращает на себя внимание факт, что области между субъединицами муцина богаты цистеином и дисульфидными связями / SH-группами (дисульфидные мостики). В желудке преобладают MUC5AC и MUC6 подтипы муцина, а в двенадцатиперстной кишке - MUC2 и MUC6 [36]. Особенности строения слизи позволяют ей быть очень эффективной линией защиты: экспозиция в условиях $\mathrm{pH} 1-8$ в гипертоническом растворе и желчи не приводит к диспергированию геля и потере реологических свойств, однако при наличии H. pylori и язвенной болезни процент мультимеров муцина снижается в пристеночном слое слизи, что указывает на уменьшение стабильности геля и ослабление защитных свойств [37]. Все вышеописанное складывается в концепцию о функциональном барьере между просветом желудка и капиллярами подслизистого слоя, основной задачей которого является «разбавлять» повреждающие агенты, замедлять их абсорбцию и тем самым сохранять эндотелий интактным. Главным образом умеренный периваскулярный отек и слизисто-бикарбонатный слой и служат этой цели. В иностранной литературе используется термин «гистодилюционный барьер» ("histodilutional barrier") [23] (рис. 3).

Какую роль в работе этого барьера играют ПГ и SH-антиоксиданты? ПГ, помимо указанных выше свойств вазодилатации и поддержания эндотелиальной функции, стимулируют секрецию бикарбонатов, фосфолипидов клеточных мембран, увеличивают текучесть и толщину слоя слизи [35], в относительно больших концентрациях подавляют секрецию $\mathrm{HCl}$. Несостоятельность теории о прямых цитопротективных свойствах ПГ была продемонстрирована в экспериментах A. Terano и соавт., А. Tarnawski и соавт., в ходе которых эффекты ПГ в культуре эпителиальных клеток в условиях in vitro не реализовывались [38, 39]. Более того, «гастропротекция» присуща ПГ (малые дозы) всех классов, включая F-группу, которые не обладают свойством снижения секреции $\mathrm{HCl}$ [23]. SH-содержащие эндогенные субстанции (L-цистеин, D, L-метионин, глутатион (GSH)) и экзогенные молекулы (MMSC, N-ацетилцистеин) предотвращают повреждение благодаря своей способности поглощать/нейтрализовывать свободные радикалы, образующиеся в избытке при клеточном повреждении под воздействием ксенобиотиков $[15,23]$. SH-соединениям присущи и другие свойства: ингибирование экспрессии TNF-a, уменьшение аспирин-индуцированной адгезии лейкоцитов к эндотелию (что привело к попыткам создания 


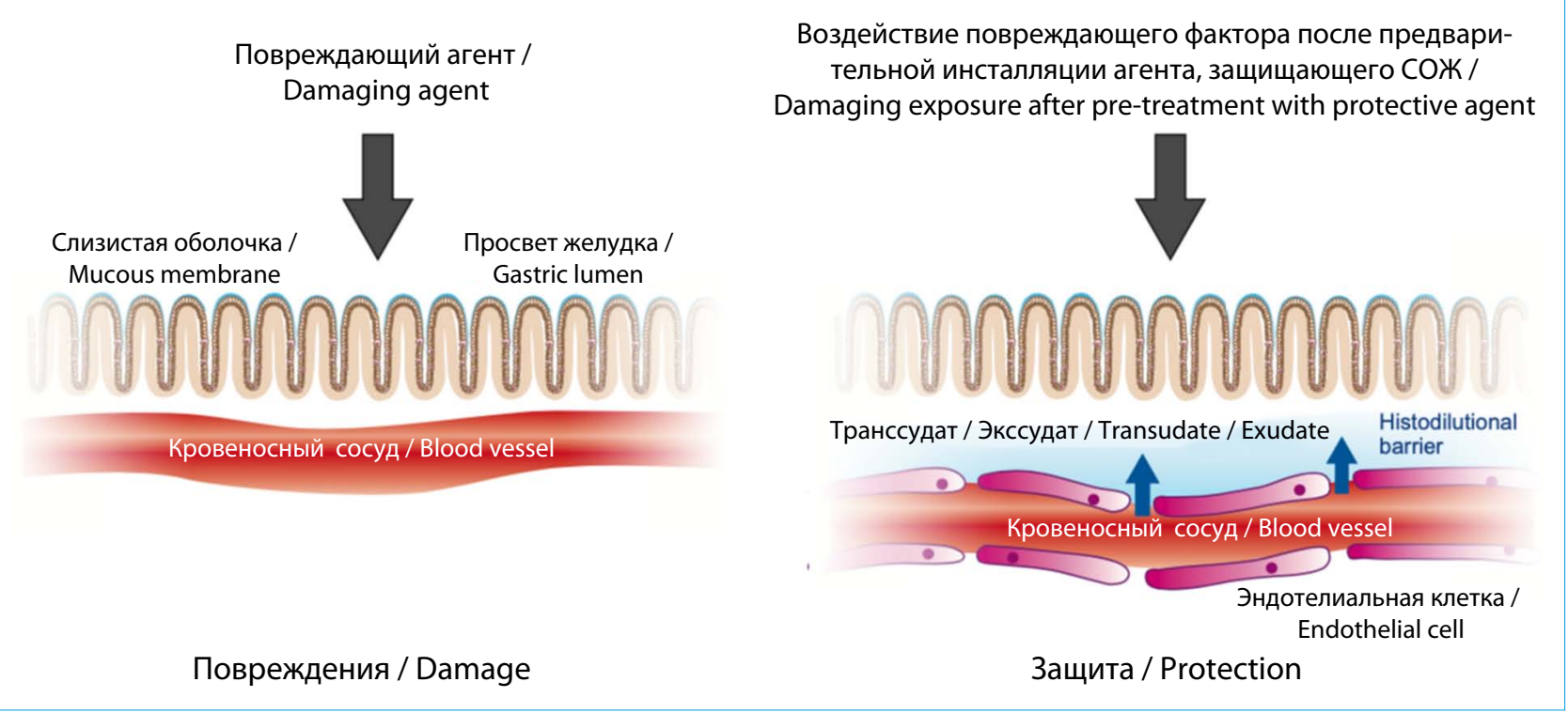

Рис. 3. «Гистодилюционный барьер» ("histodilutional barrier”) как механизм защиты слизистой желудка Fig. 3. Histodilutional barrier as a mechanism of gastric mucosa protection

НПВП-SH препаратов) [40], NO-подобное действие (вазодилатация, усиление эффектов NO) [41, 42], стимуляция высвобождения муцина [43].

\section{Хроническое повреждение}

Понятие «гастропротекция» включает в себя не только предотвращение повреждения при воздействии агрессивных агентов, но и ускорение процессов заживления в условиях сохраненной секреции соляной кислоты. Этот феномен был открыт еще на заре изучения «цитопротекции» и шел вразрез с существующей догмой «Нет кислоты нет язвы» Карла Шварца [44]. Факторы роста принимают участие и в процессе ранозаживления, и в процессе язвозаживления. Наиболее значимыми при репарации язвенного дефекта признаны фактор роста тромбоцитов (PDGF) и основной фактор роста фибробластов b (bFGF), которые участвуют в ангиогенезе и вследствие этого стимулируют образование грануляционной ткани с пролиферирующими фибробластами. Результатом их синтетической активности является коллаген, который служит своеобразными «рельсами» для клеток эпителия, мигрирующих из краев раны для закрытия язвы [45]. Точками приложения PDGF и bFGF в первую очередь являются клетки эпителия и фибробласты, однако эти факторы роста обладают разным по выраженности ангиогенным действием: bFGF превосходит по выраженности эффект PDGF $[23,45]$. In vivo фактор роста bFGF связывается с гепарином, концентрируясь в области язвенного дефекта, что необходимо для реализации его эффектов. Веществом, которое по химической структуре схоже с гепарином, оказался сукральфат и его производные, а его способность связываться c bFGF была доказана как in vitro, так и in vivo (на животной модели) [46]. Еще одной интересной находкой является тот факт, что введение сукральфата повышает содержание GSH (эндогенного источника SH-группы) в тканях желудка [46]. Что касается других SH-соединений, на животной модели продемонстрировано, что цистеин и MMSC способствовали более быстрому заживлению язв у лабораторных животных, индуцированных резерпином (вызывает вазоконстрикцию и ишемию тканей желудка): эффект был зависим от дозы и продолжительности воздействия, но его механизм не был раскрыт [47]. К сожалению, исследований влияния ПГ и $\mathrm{SH}-$ соединений на заживление язвенных дефектов СО ЖКТ при хроническом повреждении не так много.

\section{Свойства MMSC}

В настоящее время прослеживается возрождение интереса к MMSC (метилметионинсульфония хлорид), который впервые был описан в 1949 году как витамин U (U - от латинского ulcus) [48]. Витамин U по номенклатуре относится к витаминоподобным веществам и входит в состав свежих овощей. Капуста наиболее богата MMSC, отчего в недалеком прошлом ее сок широко применяли в качестве основного компонента диетотерапии при язвенной болезни $[49,50]$. Попытки объяснить механизмы действия этого вещества были воплощены в виде целого ряда исследований. Наибольшего внимания заслуживает работа T. Watanabe и соавт. [51], в ходе которой на животной модели было продемонстрировано, что и цистеин, и MMSC предотвращали этанол-индуцированное повреждение СО ЖКТ, их эффект был полностью нивелирован применением N-этилмалеимида (связывает SH-группу и не усиливает повреждение от этанола), а также стимулировали высвобождение муцина и перераспределение его на поверхность СО. В результате 
был сделан вывод о том, что MMSC, как и цистеин, является донатором SH-группы, однако, в отличие от первого, латентным, так как сульфгидрильная группа становится доступной в цепи превращения в метионин, а затем и в цистеин in vivo [51, 52]. Исследование T. Ichikawa и соавт. [53], также проведенное на животной модели, показало, что фамотидин при длительном приеме (7 дней в эксперименте) ингибирует секрецию муцина, которая восстанавливается после приема MMSC. Под воздействием последнего, как и в первом исследовании, происходило перераспределение муцина на поверхность СО ЖКТ как в группе приема MMSC, так и в группе комбинированного приема MMSC + фамотидин. Результаты этого исследования послужили свидетельством того, что MMSC может быть вспомогательным средством в комбинированных схемах лечения хронических язвенных повреждений.

И тем не менее свойства MMSC выходят за рамки только донатора SH-групп, что было доказано в целом ряде исследований: основные данные и выводы по ним обобщены в таблице 2 .

Принимая во внимание накопленные данные, к вопросу терапии патологических изменений гастродуоденальной зоны следует подходить с разных сторон и использовать разные комбинации препаратов. В связи с этим витамин $\mathrm{U}$ представляется довольно интересным и, учитывая его плейотропные эффекты, потенциально ценным средством терапии структурных нарушений гастродуоденальной зоны.

Сегодня на российском рынке витамин U представлен единственным препаратом - Гастрарекс ${ }^{\circ}$, содержащим 300 мг кристаллического MMSC, во много раз превосходящим по эффективности своего «прародителя» - капустный сок. Следует напомнить, что капуста и термически не обработанные овощи исключены из списка разрешенных продуктов в рамках диетотерапии («Стол № 1» по Певзнеру), широко рекомендованной при заболеваниях гастродуоденальной области.

Гастрарекс за счет входящего в его состав метилметионинсульфония хлорида (витамина U) обладает гастропротекторным действием, способствуя защите и укреплению слизистой оболочки желудка и двенадцатиперстной кишки; обладает антиоксидантной активностью. Благодаря способности отдавать свои метильные группы, необходимые для процессов синтеза, и влияния на холиновый

Таблица 2. Исследования, посвященные MMSC (витамину U)

Table 2. Research on MMSC (vitamin U)

\begin{tabular}{|c|c|}
\hline $\begin{array}{c}\text { Исследования } \\
\text { (автор, год) } \\
\text { Research (authors, year) }\end{array}$ & $\begin{array}{l}\text { Основные тезисы } \\
\text { General points }\end{array}$ \\
\hline Salim A.S., 1993 [61] & $\begin{array}{l}\text { Сульфгидрилсодержащие препараты значительно снижают частоту рецидивов } \\
\text { язвы двенадцатиперстной кишки } \\
\text { Sulfhydryl-containing agents essentially minimise duodenal ulcer relapse rate }\end{array}$ \\
\hline $\begin{array}{l}\text { Patel A.D. and } \\
\text { Prajapati N.K., } \\
2012[54]\end{array}$ & $\begin{array}{l}\text { Витамин U метилирует гистамин, тем самым инактивируя его, в результате } \\
\text { снижается секреция HCl } \\
\text { Vitamin U methylates histamine, hence inactivating it and leading to reduced } \mathrm{HCl} \\
\text { secretion }\end{array}$ \\
\hline $\begin{array}{l}\text { Nakamura N. et al., } \\
1981 \text { [55] }\end{array}$ & $\begin{array}{l}\text { MMSC обладает липотропным действием: снижает уровень общего холестерина } \\
\text { и ЛПНП в крови. Стабилизирует проницаемость клеточных мембран, } \\
\text { препятствуя жировой инфильтрации печени } \\
\text { MMSC exerts lipotropic effect: lowers total blood cholesterol and LDL. Stabilises } \\
\text { cell membrane permeability, prevents fatty liver infiltration } \\
\text { Влияет на жировой обмен посредством ингибирования дифференцировки } \\
\text { адипоцитов и стимуляции активности АМФ-активируемой протеинкиназы } \\
\text { (AMPK) } \\
\text { Affects lipid metabolism via adipocyte differentiation inhibition and AMPK (AMP- } \\
\text { activated protein kinase) activation }\end{array}$ \\
\hline $\begin{array}{l}\text { Tunali S. et al., } \\
2014[57] \\
\text { Sokmen B.B. et al., } \\
2012[58]\end{array}$ & $\begin{array}{l}\text { Выступает в роли антиоксиданта при клеточном повреждении не только } \\
\text { в желудочном эпителии: витамин U эффективно устранял индуцированный } \\
\text { вальпроевой кислотой оксидативный стресс, лежащий в основе повреждения } \\
\text { хрусталика глаза [57] (осложнение противоэпилептической терапии) и } \\
\text { паренхимы печени [58] } \\
\text { Acts as antioxidant in cell damage, also outside gastric epithelium: vitamin U } \\
\text { effectively reduces valproic acid-induced oxidative stress exerting eye lens [57] } \\
\text { (in complication of antiepileptic therapy) and hepatic parenchyma lesions [58] }\end{array}$ \\
\hline Kim et al., 2015 [60] & $\begin{array}{l}\text { Местное нанесение витамина U стимулировало ускорение процесса } \\
\text { ранозаживления посредством активации фибробластов } \\
\text { Tорісаl application of vitamin U promotes wound-healing via fibroblast activation } \\
\text { Фотопротективное свойство: MMSC уменьшал UV-индуцированное повреждение } \\
\text { кожи } \\
\text { Photoprotectivity: MMSC reduces UV-induced skin damage }\end{array}$ \\
\hline
\end{tabular}


обмен, Гастрарекс стимулирует выработку муцина клетками слизистой оболочки ЖКТ, что способствует повышению ее защитной функции от агрессивных факторов внутренней и внешней среды и активизирует процессы восстановления клеток гастродуоденальной слизистой оболочки за счет непосредственной регенерации эпителиоцитов желудка и двенадцатиперстной кишки.

Гастрарекс безопасен в применении, случаев передозировки не было зарегистрировано, что позволяет рекомендовать данный препарат в качестве дополнения к современным схемам терапии эрозивно-язвенного повреждения СО ЖКТ и НПВПгастропатии. Дальнейшие исследования необходимы в данной области.

На сегодняшний день Гастрарекс проходит клинические испытания на кафедре пропедевтики внутренних болезней, гастроэнтерологии и гепатологии Института клинической медицины им. Н.В. Склифосовского ФГАОУ ВО «Первый МГМУ им. И.М. Сеченова» Минздрава России (Сеченовский Университет) с целью изучения его эффективности у пациентов с хроническим гастритом, в том числе с эрозивным. Все пациенты получают основную терапию и препарат Гастрарекс (300 мг S-метилметионинсульфония хлорид) по 1 капсуле 1 раз в день. До начала исследования и после курса терапии проведена ЭГДС. При каждом визите к врачу пациенты заполняли

\section{Литература / References}

1. Ивашкин В.Т., Маев И.В., Лапина Т.Л., Шептулин А.А., Трухманов А.С., Баранская Е.К. и др. Клинические рекомендации Российской гастроэнтерологической ассоциации по диагностике и лечению инфекции Helicobacter pylori у взрослых. Российский журнал гастроэнтерологии гепатологии колопроктологии. 2018;28(1):55-70. [Ivashkin V.T., Mayev I.V., Lapina T.L., Sheptulin A.A., Trukhmanov A.S., Baranskaya Y.K., et al. Diagnostics and treatment of Helicobacter pylori infection in adults: Clinical guidelines of the Russian gastroenterological association. Rus J Gastroenterol Hepatol Coloproctol. 2018;28(1):55-70 (In Russ.)]. DOI: 10.22416/1382-4376-2018-28-1-55-70

2. Каратеев А.Е., Насонов Е.Л., Ивашкин В.Т., Мартынов А.И., Яхно Н.Н., Арутюнов Г.П. и др. Рациональное использование нестероидных противовоспалительных препаратов. Клинические рекомендации. Научно-практическая ревматология. 2018;56:1-29. [Karateev A.E., Nasonov E.L., Ivashkin V.T., Martynov A.I., Yakhno N.N., Arutyunov G.P. et al. Rational use of nonsteroidal anti-inflammatory drugs. Clinical guidelines. Rheumatology Science and Practice. 2018;56:1-29. (In Russ.)] DOI: 10.14412/1995-4484-2018-1-29

3. Назаров B.E. Причины безуспешности эрадикационной терапии, не связанные с антибиотикорезистентностью Helicobacter pylori, и пути их преодоления. РМЖ. Медицинское обозрение. 2018;26(3):4-12. [Nazarov V.E. Failures of eradication therapy unrelated to Helicobacter pylori antibiotic resistance and routes to their solution. RMJ. Medical Review. 2018. 26(3):4-12. (In Russ.)].

4. Евсеев M.A. НПВП-индуцированные гастродуоденальные язвы, осложненные кровотечением. РМЖ. 2006;15:1099-107. [Evseev M.A. NSAID-induced bleeding-complicated gastroduodenal ulcers. RMJ. 2006;15:1099-107. (In Russ.)].

5. Шостак Н.А., Рябкова А.А., Савельев В.С., Малярова Л.П. Желудочно-кишечное кровотечение как ослож- опросник боли, свидетельствующий об изменении симптоматики заболевания. Результаты исследования мы планируем опубликовать после статистической обработки.

\section{Заключение}

Таким образом, накопленные экспериментальные данные за последние 40 лет прямо свидетельствуют о том, что препараты, чьей точкой приложения являются разные уровни защиты СО желудка и двенадцатиперстной кишки, не перестают быть объектом интереса практической медицины. Это обусловлено постоянным поиском новых подходов к совершенствованию и адаптации схем терапии к пациентам с особенностями течения различных гастродуоденальных заболеваний и коморбидным статусом. Психоэмоциональный стресс, вызванный осложнениями и побочными эффектами от лечения фармпрепаратами, недоверие и предубеждения относительно проводимой терапии могут приводить к снижению комплаенса пациентов, отказу от соблюдения предписаний врача, ухудшению качества ремиссии. Все перечисленное говорит об актуальности «гастропротекторов», одним из которых выступает MMSC (витамин U). Витамин U является биологически активным веществом, и его роль ограничена рамками вспомогательного средства, сопровождающего основные схемы лечения.

нение гастропатий, связанных с приемом нестероидных противовоспалительных препаратов. Терапевтический архив. 2003;5:70-4. [Shostak N.A., Ryabkova A.A., Savelyev V.S., and Malyarova L.P. Gastrointestinal bleeding as complication of NSAID-associated gastropathies. Terapevticheskiy archiv. 2003;5:70-4. (In Russ.)].

6. Washio E., Esaki M., Maehata Y., Miyazaki M., Kobayashi H., Ishikawa $H$., et al. Proton Pump Inhibitors Increase Incidence of Nonsteroidal Anti-Inflammatory Drug-Induced Small Bowel Injury: A Randomized, Placebo-Controlled Trial. Clin. Gastroenterol. Hepatol. 2016;14(6):809-15. DOI: 10.1016/j.cgh.2015.10.022

7. Flores M., Glusman G., Brogaard K., Price N.D., Hood L. P4 medicine: How systems medicine will transform the healthcare sector and society. Personalized Medicine. 2013;10(6):565-76. DOI: 10.2217/pme.13.57

8. Robert $A$. Antisecretory and antiulcer properties of prostaglandins. Compr Ther. 1978;4(7):3-10.

9. Robert A., Nezamis J.E., Lancaster C. Duodenal ulcers produced in rats by propionitrile: factors inhibiting and aggravating such ulcers. Toxicol Appl Pharmacol. 1975;31(2):201-7. DOI: 10.1016/0041-008x(75)90156-8

10. Robert A., Nezamis J.E., Lancaster C., Hanchar A.J. Cytoprotection by prostaglandins in rats. Prevention of gastric necrosis produced by alcohol, $\mathrm{HCl}, \mathrm{NaOH}$, hypertonic $\mathrm{NaCl}$, and thermal injury. Gastroenterology. 1979;77(3):433-43. DOI: 10.1016/0016-5085(79)90002-7

11. Robert A. Cytoprotection by prostaglandins. Gastroenterology. 1979;77(4):761-7. DOI: 10.1016/00165085(79)90235-X

12. Guth P.H., Aures D., Paulsen G. Topical aspirin plus $\mathrm{HCl}$ gastric lesions in the rat. Cytoprotective effect of prostaglandin, cimetidine, and probanthine. Gastroenterology. 1979;76(1):88-93. DOI: 10.1016/S0016-5085(79)80133-X

13. Szabo S., Gallagher G.T., Horner H.C., Frankel P.W., Underwood R.H., Konturek S.J., et al. Role of the 
Adrenal Cortex in Gastric Mucosal Protection by Prostaglandins, Sulfhydryls, and Cimetidine in the Rat. Gastroenterology. 1983;85(6):1384-90. DOI: 10.1016/S0016 5085(83)80022-5

14. Szabo S., Tache Y., Tarnawski A. The 'gastric cytoprotection' concept of Andre Robert and the origins of a new series of international symposia. Cell/Tissue Inj Cytoprot Gastrointest Tract Mech Prev Treat. 2012;30:1-23. DOI: $10.1159 / 000338742$

15. Szabo S., Trier J.S., Frankel P.W. Sulfhydryl compounds may mediate gastric cytoprotection. Science. 1981;214(4571):200-2. DOI: 10.1126/science.7280691

16. Lacy E.R., Ito $S$. Microscopic analysis of ethanol damage to rat gastric mucosa after treatment with a prostaglandin. Gastroenterology. 1982;83:619-25. DOI: 10.1016/S0016 5085(82)80198-4

17. Lacy E.R., Ito $S$. Rapid epithelial restitution of the rat gastric mucosa after ethanol injury. Lab Invest. 1984;51(5):573-83.

18. Szabo S., Trier J.S., Brown A., Schnoor J. Early vascular injury and increased vascular permeability in gastric mucosal injury caused by ethanol in the rat. Gastroenterology. 1985;88(1):228-36. DOI: 10.1016/s0016-5085(85)80176-1

19. Szabo S., Szelenyi I. 'Cytoprotection' in gastrointestinal pharmacology. Trends in Pharmacological Sciences. Elsevier Current Trends. 1987;8(4):149-54. DOI: 10.1016/0165 6147(87)90185-4

20. Ивашкин B.T., Маев И.В., Ивашкин К.В., Корочан ская Н.В., Лопина О.Д., Лапина Т.Л. и др. Роль нарушения защитных факторов в развитии кислотозависимых заболеваний (Резолюция Экспертного совета 12-13 марта 2016). Российский журнал гастроэнтерологии, гепатологии, колопроктологии. 2016;26(3):115-6. [Ivashkin V.T., Mayev I.V., Ivashkin K.V., Korochanskaya N.V., Lopina O.D., Lapina T.L. et al. Protection factor disorders in acid-related diseases (Expert Council Resolution of 12-13 March, 2016). Rus J Gastroenterol Hepatol Coloproctol. 2016;26(3):115-6 (In Russ.)]. DOI: 10.22416/1382-4376-2016-26-3-115-116

21. Laine L., Takeuchi K., Tarnawski A. Gastric Mucosal Defense and Cytoprotection: Bench to Bedside. Gastroenterology. 2008;135(1):41-60. DOI: $10.1053 /$ j.gas tro.2008.05.030

22. Trier J.S., Szabo S., Allan C.H. Ethanol-induced damage to mucosal capillaries of rat stomach. Ultrastructural features and effects of prostaglandin F2 $\beta$ and cysteamine. Gastroenterology. 1987;92(1):13-22. DOI: 10.1016/00165085(87)90834-1

23. Szabo $S$. 'Gastric cytoprotection' is still relevant. J. Gastroenterol. Hepatol. 2014;29(S4):124-32. DOI: 10.1111/ jgh. 12735

24. Leung F.W., Robert A., Guth P.H. Gastric mucosal blood flow in rats after administration of 16,16-dimethyl prostaglandin E2 at a cytoprotective dose. Gastroenterology. 1985;88(6):1948-53. DOI: 10.1016/0016-5085(85)90024-1

25. Самсонов А.А., Голубев Н.Н., Андреев Н.Г., Щербакова Н.А. Защитный барьер слизистой оболочки желудка и возможности лекарственной цитопротекции. Справочник поликлинического врача. 2018;6:40-8. [Samsonov A.A., Golubev N.N., Andreev N.G., Shcherbakova N.A. Gastric mucosa protective barrier and prospects of drug cytoprotection. Spravochnik poliklinicheskogo vracha. 2018;6:40-8 (In Russ.)].

26. Tarnawski A., Stachura J., Gergely H., Hollander D. Microvascular endothelium-a major target for alcohol in jury of the human gastric mucosa. Histochemical and ultrastructural study. J Clin Gastroenterol. 1988;10(Suppl 1):53-64.

27. Kumar V., Abbas A.K., Fausto N., Aster J.C. Robbins and Cotran Pathologic Basis of Disease, Professional Edition: Expert Consult-Online. 2009.

28. Mozsik G., Szabo I.L., Czimmer J. Approaches to Gastrointestinal Cytoprotection: From Isolated Cells, Via Animal Experiments to Healthy Human Subjects and Patients with Different Gastrointestinal Disorders. Curr Pharm Des. 2011;17(16):1556-72. DOI: 10.2174/138161211796197016
29. Peskar B.M. Neural aspects of prostaglandin involvement in gastric mucosal defense. J Physiol Pharmacol. 2001;52(4):555-68. PMID: 11787758

30. Kang J.Y., Teng C.H., Chen F.C., Wee A. Role of capsaicin sensitive nerves in epidermal growth factor effects on gastric mucosal injury and blood flow. Gut. 1998;42(3):344-50. DOI: 10.1136/gut.42.3.344

31. Holzer $P$. Neural regulation of gastrointestinal blood flow. Physiology of the gastrointestinal tract. 4th Edition. New York: Academic Press. 2006:817-39.

32. Holzer $P$. Role of visceral afferent neurons in mucosal inflammation and defense. Current Opinion in Pharmacology. 2007;7(6):563-9. DOI: 10.1016/j.coph.2007.09.004

33. Robert A. Cytoprotection and adapted cytoprotection. Peptic Ulcer Disease: Basic and Clinical Aspects. Springer Netherlands. 1985:297-316.

34. Kokoska E.R., Smith G.S., Deshpande Y., Rieckenberg C.L., Miller T.A. Adaptive cytoprotection induced by ethanol in human intestinal cells: Role of prostaglandins and calcium homeostasis. Ann Surg. 1988;228(1):123-30. DOI: $10.1097 / 00000658-199807000-00018$

35. Allen A., Flemström G. Gastroduodenal mucus bicarbonate barrier: Protection against acid and pepsin. Am J Physiol - Cell Physio. 2005;288(1):57-61. DOI: 10.1152/ajpcell.00102.2004

36. Ribeiro A.R.S., Valenca J.D.N., Santos J.S., Boeing Th., Silva L.M., Andrade S.F., et al. The effects of baicalein on gastric mucosal ulcerations in mice: Protective pathways and anti-secretory mechanisms. Chem Biol Interact. 2016;260:33-41. DOI: 10.1016/j.cbi.2016.10.016

37. Celli J.P., Turner B.S., Afdhal N.H., Keates S., Ghiran I., Kelly C.P., et al. Helicobacter pylori moves through mucus by reducing mucin viscoelasticity. Proc Natl Acad Sci USA. 2009;106(34):14321-6. DOI: 10.1073/ pnas.0903438106

38. Terano A., Mach T., Stachura J., Tarnawski A., Ivey K.J. Effect of 16,16 dimethyl prostaglandin E2 on aspirin induced damage to rat gastric epithelial cells in tissue culture. Gut. 1984;25(1):19-25. DOI: 10.1136 / gut.25.1.19

39. Tarnawski A., Brzozowski T., Sarfeh I.J., Krause W.J., Ulich T.R., Gergely H., et al. Prostaglandin protection of human isolated gastric glands against indomethacin and ethanol injury. Evidence for direct cellular action of prostaglandin. J Clin Invest. 1988;81(4):1081. DOI: 10.1172/ JCI113420

40. Ham M., Kaunitz J.D. Gastroduodenal defense. Curr Opin Gastroenterol. 2007;23(6):607-16. DOI: 10.1097/ MOG.0b013e3282f02607

41. Fiorucci S., Antonelli E., Distrutti E., Rizzo G., Mencarelli A., Orlandi $S$., et al. Inhibition of hydrogen sulfide generation contributes to gastric injury caused by anti-inflammatory nonsteroidal drugs. Gastroenterology. 2005;129(4):1210-24. DOI: $10.1053 /$ j.gastro.2005.07.060

42. Fiorucci S., Distrutti E., Cirino G., Wallace J.L. The Emerging Roles of Hydrogen Sulfide in the Gastrointestinal Tract and Liver. Gastroenterology. 2006;131(1):25971. DOI: $10.1053 /$ j.gastro.2006.02.033

43. Lamont J.T., Ventola A.S., Maull E.A., Szabo S. Cysteamine and prostaglandin F2 beta stimulate rat gastric mucin release. Gastroenterology. 1983;84(2):306-13.

44. Gustafson J., Welling D. 'No Acid, No Ulcer' - 100 Years Later: A Review of the History of Peptic Ulcer Disease. J Am Coll Surg. 2010; 210(1):110-6. DOI: 10.1016/j.jamcollsurg.2009.08.014

45. Szabo S., Vincze A. Growth factors in ulcer healing: lessons from recent studies. J. Physiol. Paris. 2000;94(2):7781. DOI: 10.1016/s0928-4257(00)00146-7

46. Sandor Z., Nagata M., Kusstatscher S., Szabo S. Stimulation of mucosal glutathione and angiogenesis: New mechanisms of gastroprotection and ulcer healing by sucralfate. Scand J Gastroenterol. 1995;30(S210):19-21. DOI: $10.3109 / 00365529509090263$

47. Salim A.S. Role of sulfhydryl-containing agents in the healing of erosive gastritis and chronic gastric ulceration 
in the rat. J Pharm Sci. 1992;81(1):70-3. DOI: 10.1002/ jps.2600810114

48. Cheney G. Anti-peptic ulcer dietary factor (vitamin ' $U$ ') in the treatment of peptic ulcer. J Am Diet Assoc. 1950;26(9):668-72.

49. Нестерова А.П., Тайи Н.С. Опыт применения витами на $\mathrm{U}$ в комплексном лечении язвенной болезни. Институт питания АМН CCCP. Витамин U (S-Метилметионин). Природа, свойства, применение. М.: Наука, 1973:53-60. [Nesterova A.P., Tayts N.S. Application of vitamin U in complex peptic ulcer therapy. Institute of Nutrition, USSR Academy of Medical Sciences. Vitamin U (S-methylmethionine). Nature, properties and application. Moscow: Nauka, 1973:53-60 (In Russ.)].

50. Самсон Е.И., Луканев Г.Д. Терапевтическая эффективность применения витамина $U$ при язвенной болезни. Институт питания АМН СССР Витамин U (S-Метилметионин). Природа, свойства, применение. M.: Наука, 1973:96-101. [Samson E.I., Lukanev G.D. Therapeutic efficacy of vitamin $U$ in peptic ulcer. Institute of Nutrition, USSR Academy of Medical Sciences. Vitamin U (S-methylmethionine). Nature, properties and application. Moscow: Nauka, 1973:96-101 (In Russ.)].

51. Watanabe T., Ohara S., Miyazawa S., Saigenji K., Hotta K. Augmentative effects of L-cysteine and methylmethionine sulfonium chloride on mucin secretion in rabbit gastric mucous cells. J Gastroenterol Hepatol. 2000;15(1):45-52. DOI: $10.1046 / j .1440-1746.2000 .02037 . x$

52. Watanabe T., Ohara S., Ichikawa T., Saigenji K., Hotta $K$. Mechanisms for cytoprotection by vitamin $U$ from ethanol-induced gastric mucosal damage in rats. Dig Dis Sci. 1996;41(1):49-54. DOI: 10.1007/BF02208583

53. Ichikawa T., Ito Y., Saegusa Y., Irwai T., Goso Y., Ikezawa T., et al. Effects of combination treatment with famotidine and methylmethionine sulfonium chloride on

\section{Сведения об авторах}

Ивашкин Константин Владимирович* - кандидат меди цинских наук, доцент кафедры пропедевтики внутренних болезней Института клинической медицины им. Н.В. Склифосовского ФГАОУ ВО «Первый Московский государственный медицинский университет им. И.М. Сеченова» (Сеченовский Университет) Министерства здравоохранения Российской Федерации.

Контактная информация: 2135833@mail.ru;

119435, г. Москва, ул. Погодинская, д. 1, стр. 1.

ORCID: https://orcid.org/0000-0002-5699-541X

Изатуллаев Ельдос Абдыкаликович - доктор медицинских наук, профессор, академик АКФМ, Объединенная клиника Казахстанского национального медицинского университета им. С.Д. Асфендиярова на базе Образовательно-клинического центра, руководитель Центра гастроэнтерологии и эндоскопической диагностики.

Контактная информация: iza2la@mail.ru;

480072, Казахстан, Алматы, ул. Муратбаева, д. 211.

Корнеева Василиса Романовна - ординатор кафедры пропедевтики внутренних болезней, гастроэнтерологии и гепатологии Института клинической медицины им. Н.В. Склифосовского ФГАОУ ВО «Первый Московский государственный медицинский университет им. И.М. Сеченова» (Сеченовский Университет) Министерства здравоохранения Российской Федерации.

Контактная информация: k.vasilis@mail.ru;

119991, Москва, ул. Погодинская, д. 1, стр. 1.

ORCID: https://orcid.org/0000-0002-3851-626X the mucus barrier of rat gastric mucosa. J Gastroenterol Hepatol. 2009;24(3):488-92. DOI: 10.1111/j.14401746.2008.05667.x

54. Patel A.D., Prajapati N.K. Review on Biochemical Importance of Vitamin-U. J Chem Pharm Res. 2012;1:209-15.

55. Nakamura N., Uzawa H., Kanazawa K., Tamai Y., Tashiro Y., Koide M. Hypolipidemic effect of L-form Smethylmethionine sulfonium chloride in man. ArzneimittelForschung/Drug Res. 1981;31(4):725-9. PMID: 7195721

56. Lee N.Y., Park K.Y., Min H.J., Song K.Y. Inhibitory effect of vitamin U (S-methylmethionine sulfonium chloride) on differentiation in 3T3-L1 pre-adipocyte cell lines. Ann Dermatol. 2012;24(1):39-44. DOI: 10.5021 ad.2012.24.1.39

57. Tunali S., Kahraman S., Yanardag R. Vitamin U, a novel free radical scavenger, prevents lens injury in rats administered with valproic acid. Hum Exp Toxicol. 2015;34(9):904-10. DOI: 10.1177/0960327114561665

58. Sokmen B.B., Tunali S., Yanardag R. Effects of vitamin $\mathrm{U}$ (S-methyl methionine sulphonium chloride) on valproic acid induced liver injury in rats. Food Chem Toxicol. 2012;50(10):3562-6. DOI: 10.1016/j.fct.2012.07.056

59. Kim W.S., Yang Y.J., Min H.G., Song M.G., Lee J.S., Park K.Y., et al. Accelerated Wound Healing by S-Methylmethionine Sulfonium: Evidence of Dermal Fibroblast Activation via the ERK1/2 Pathway. Pharmacology. 2010;85(2):68-76. DOI: 10.1159/000276495

60. Kim W.S., Seo H.M., Kim W.K., Choi J.S., Kim I., Sung J.H. The photoprotective effect of S-methylmethionine sulfonium in skin. Int J Mol Sci. 2015;16(8):17088100. DOI: $10.3390 / \mathrm{ijms} 160817088$

61. Salim A.S. Sulphydryl-containing agents and the prevention of duodenal ulcer relapse. Pharmacology. 1993;46(5):281-8. DOI: 10.1159/000139056

\section{Information about the authors}

Konstantin V. Ivashkin* - Cand. Sci. (Med.), Ass. Prof., Department of Internal Disease Propaedeutics, Sklifosovskiy Institute of Clinical Medicine, I.M. Sechenov First Moscow State Medical University.

Contact information: 2135833@mail.ru;

119435, Russian Federation, Moscow, Pogodinskaya str., 1, build. 1.

ORCID: https://orcid.org/0000-0002-5699-541X

Eldos A. Izatullaev - Academician of the ACFM, Dr. Sci. (Med.), Prof., United clinic of S.D. Asfendiyarov Kazakhstan National Medical University based in Educational clinical Centre. Head of gastroenterology and endoscopic diagnostic Centre.

Contact information: iza2la@mail.ru;

480072, Kazakhstan, Almaty, Muratbaeva str., 211.

Vasilisa R. Korneeva - Clinical Intern, Department of Internal Disease Propaedeutics, Sklifosovskiy Institute of Clinical Medicine, I.M. Sechenov First Moscow State Medical University.

Contact information: k.vasilis@mail.ru;

119435, Russian Federation, Moscow, Pogodinskaya str., 1, build. 1.

ORCID: https://orcid.org/0000-0002-3851-626X

Поступила: 07.08.2020 Принята: 07.09.2020 Online first: 05.10.2020 Опубликована: 30.10.2020 Submitted: 07.08.2020 Accepted: 07.09.2020 Online first: 05.10.2020 Published: 30.10.2020

* Автор, ответственный за переписку / Corresponding author 